\title{
High Frequency of Low-Virulent Microorganisms Detected by Sonication of Implanted Pulse Generators: So What?
}

\author{
Philipp Spindler ${ }^{a}$ Katharina Faust ${ }^{a}$ Tobias Finger ${ }^{a}$ Gerd-Helge Schneider ${ }^{a}$ \\ Simon Bayerl ${ }^{a}$ Andrej Trampuz ${ }^{b}$ Andrea A. Kühn ${ }^{c}$ Peter Vajkoczy ${ }^{a}$ \\ Vincent Prinz ${ }^{a}$ d \\ aDepartment of Neurosurgery and Center for Stroke research Berlin (CSB), Charité-Universitätsmedizin Berlin, \\ Corporate Member of Freie Universität Berlin, Humboldt-Universität zu Berlin and Berlin Institute of Health,

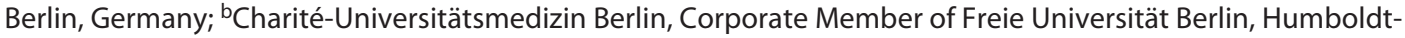 \\ Universität zu Berlin and Berlin Institute of Health, Center for Musculoskeletal Surgery (CMSC), Berlin, Germany; \\ 'Department of Neurology, Movement Disorder and Neuromodulation Unit, Charité-Universitätsmedizin Berlin,

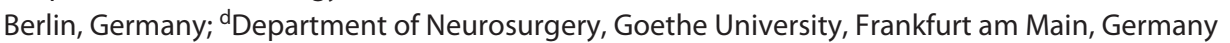

\section{Keywords}

Antimicrobial treatment · Biofilm · Complications · Deep

brain stimulation · Low-virulent infection · Sonication

\begin{abstract}
Introduction: Deep brain stimulation (DBS) has become a well-established treatment modality for a variety of conditions over the last decades. Multiple surgeries are an essential part in the postoperative course of DBS patients if nonrechargeable implanted pulse generators (IPGs) are applied. So far, the rate of subclinical infections in this field is unknown. In this prospective cohort study, we used sonication to evaluate possible microbial colonization of IPGs from replacement surgery. Methods: All consecutive patients undergoing IPG replacement between May 1, 2019 and November 15, 2020 were evaluated. The removed hardware was investigated using sonication to detect biofilm-associated bacteria. Demographic and clinical data were analyzed. Results: A total of 71 patients with a mean $( \pm$ SD) of $64.5 \pm$
\end{abstract}

karger@karger.com www.karger.com/sfn

Karger $\stackrel{\text { ' }}{5}$

BOPEN ACCESS
(C) 2021 The Author(s)

Published by S. Karger AG, Basel

This article is licensed under the Creative Commons Attribution 4.0 International License (CC BY) (http://www.karger.com/Services/ OpenAccessLicense). Usage, derivative works and distribution are permitted provided that proper credit is given to the author and the original publisher.
15.3 years were evaluated. In 23 of these (i.e., 32.4\%) patients, a positive sonication culture was found. In total, 25 microorganisms were detected. The most common isolated microorganisms were Cutibacterium acnes (formerly known as Propionibacterium acnes) (68\%) and coagulase-negative Staphylococci (28\%). Within the follow-up period (5.2 \pm 4.3 months), none of the patients developed a clinical manifest infection. Discussions/Conclusions: Bacterial colonization of IPGs without clinical signs of infection is common but does not lead to manifest infection. Further larger studies are warranted to clarify the impact of low-virulent pathogens in clinically asymptomatic patients.

(C) 2021 The Author(s)

Published by S. Karger AG, Basel

\section{Introduction}

Deep brain stimulation (DBS) has become a widely used treatment option for a variety of conditions over the past 3 decades $[1,2]$. Besides appropriate preoperative

Correspondence to:

Peter Vajkoczy, peter.vajkoczy@charite.de 
evaluation of potential surgical candidates, maximum precision in planning of target regions, highly accurate implantation of electrodes, and most importantly continuous postoperative care after DBS hardware placement are crucial parts of DBS therapy. In case of nonrechargeable implanted pulse generators (IPGs), replacement of the IPGs is necessary after approximately 8.5-110.5 months [3]. Thus, multiple surgeries are an essential part in the postoperative course of DBS patients. Repetitive surgeries have been described as a risk factor for surgical site infections (SSIs) [4]. The rate of infections of IPG replacements is about 4.8\% (range 0-17.6\%) [5-9]. The majority of infections associated with DBS hardware occur early within one month after implantation. The infection rate is about $5.6 \%$ (range $0-15 \%$ ), with $52 \%$ manifesting as early infections within the 1 st month after implantation $[6,10,11]$. Implantable devices are highly susceptible to bacterial colonization, and even a low number of bacteria can cause infections [12]. A wide range of pathogens has been found in microbiological cultures of DBS hardware removal $[5,6,8,13]$, yet microorganisms typically adhere to the surface of the devices and form biofilms, making them difficult to be detected by conventional methods [14]. By means of sonication, microorganisms can be released from the implant's surface and quantitatively and qualitatively be detected from the detached biofilm in the sonication fluid. Sensitivity and specificity of sonication have been demonstrated as significantly higher than those of standard tissue cultures. Recent data showed that sonication of neurosurgical devices as well as pedicle screws is associated with a significantly higher rate of bacterial growth than that in conventional cultures, especially with respect to low-virulent pathogens [14-17]. Thus, to optimize detection of potentially biofilm-associated infections, sonication of removed devices and prolonged incubation of cultures have been recommended [18]. Recent data found implant-associated low-virulent microorganisms in clinically aseptic patients as a potential cause for implant failure with regard to pedicle screws as well as autologous bone graft resorption after cranioplasty [18-22]. In this prospective cohort study, we used sonication to evaluate possible microbial colonization of IPGs from replacement surgery.

\section{Methods}

\section{Study Design}

This prospective observational study was conducted in a tertiary health-care center providing advanced specialty care to a population of about 4 million inhabitants. The study was conducted in accordance with the Declaration of Helsinki and approved by the Local Ethics Committee (No. EA2/231/20). Patient consent was not required for this prospective observational study as sonication was performed as part of the routine microbiological investigation.

\section{Study Population}

Between May 1, 2019, and November 15, 2020, a total of 71 consecutive adult patients in whom an IPG exchange due to depletion of the battery was performed were screened. None of the patients was on antibiotic therapy prior to IPG replacement. All patients were closely followed up postoperatively in our outpatient department.

\section{Data Collection}

Patient data were collected using a standardized case report form. An interdisciplinary team of neurosurgeons and infection disease specialists evaluated all patients. The following variables were extracted: age, sex, comorbidities (diabetes, smoking status, steroid use, and BMI), the underlying indication for DBS, time between initial surgery and explantation of IPGs, number of former replacements of IPGs if applicable, indication for explantation of DBS hardware, laboratory values at admission (i.e., C-reactive protein [CRP], white blood cell count, and $\mathrm{Hb}$ ), and microbiological results of the sonication fluid.

\section{Surgical Procedure}

All surgical procedures were performed according to a standardized routine under sterile conditions in the operating room. All patients received a single dose of perioperative antibiotics (2.0 $\mathrm{g}$ of intravenous cefazolin) $30 \mathrm{~min}$ prior to skin incision. An alcoholic skin antiseptic with a remanent effect was used for initial implantation and replacements. Double gloving with an exchange of the superficial gloves before placement of the new IPG was performed. For irrigation of the incisional wound, we used an aqueous povidone-iodine solution. The wounds were closed in layers with non-antibiotic-impregnated absorbable subcutaneous sutures and either monofilament nonabsorbable sutures or staples. For postoperative dressing, we used standard dressing that was exchanged daily until removal of the sutures 10-12 days after surgery. There was no prolongation of postoperative surgical antibiotic prophylaxis. Immediately after removal of the IPG, it was placed in a sterile, airtight container to minimize the risk of contamination; removed implants were sent for analysis.

\section{Sonication of Removed Implants}

The removed IPGs were transported to the microbiological laboratory in a sterile airtight container (Lock \& Lock). Within 6 h of removal, sonication was performed. After addition of $5 \mathrm{~mL}$ of normal saline covering the implants, the container was vortexed for 30 s, sonicated for 1 min at $40 \mathrm{kHz}$ (BactoSonic, Bandelin, Berlin, Germany), and vortexed for another $30 \mathrm{~s}$. The resulting sonication fluid was processed as conventional cultures. Microorganisms on plates were enumerated (i.e., number of colony-forming units/mL sonication fluid) and identified using routine microbiological techniques.

\section{Statistical Analysis}

Statistical analyses were performed with GraphPad Prism (version 8.4.2 [464]). Unpaired Student's $t$ test and Fisher's exact test were used to compare the cohorts. All statistical tests were 2-tailed, and statistical significance was set at $p<0.05$. 
Table 1. Demographic and clinical data

\begin{tabular}{|c|c|c|c|c|}
\hline $\begin{array}{l}\text { Parameter } \\
\text { Mean }( \pm S D) \text { or absolute numbers }\end{array}$ & $\begin{array}{l}\text { All patients } \\
(n=71)\end{array}$ & $\begin{array}{l}\text { Sonication } \\
\text { positive }(n=23)\end{array}$ & $\begin{array}{l}\text { Sonication } \\
\text { negative }(n=48)\end{array}$ & $p$ value \\
\hline Age, years & $64.5( \pm 15.3)$ & $62.5( \pm 15.3)$ & $65.5( \pm 15.2)]$ & 0.4 \\
\hline Sex, \% male & 53.6 & 73.9 & 43.8 & 0.02 \\
\hline \multicolumn{5}{|l|}{ Indication for DBS } \\
\hline Parkinson's disease & 38 & 12 & 26 & 0.6 \\
\hline Dystonia & 22 & 6 & 16 & 0.7 \\
\hline Essential tremor & 9 & 5 & 4 & 0.4 \\
\hline OCD & 1 & - & 1 & 0.7 \\
\hline Depression & 1 & - & 1 & 0.4 \\
\hline Time since lead implantation, years & $6.6( \pm 3.4)$ & $6.8( \pm 4.0)$ & $6.5( \pm 2.9)$ & 0.8 \\
\hline First IPG replacements, $n$ & 21 & 5 & 16 & 0.4 \\
\hline Former IPG replacements & $1.1( \pm 1.1)$ & $1.1( \pm 1.1)$ & $1.0( \pm 1.0)$ & 0.8 \\
\hline \multicolumn{5}{|l|}{ Laboratory values at admission } \\
\hline $\mathrm{CRP}, \mathrm{mg} / \mathrm{L}$ & $7.2( \pm 12.9)$ & $1.8( \pm 0.8)$ & $10.3( \pm 15.3)$ & 0.2 \\
\hline White blood cell count, $n / \mathrm{nL}$ & $6.5( \pm 1.2)$ & $6.2( \pm 0.9)$ & $6.8( \pm 1.4)$ & 0.5 \\
\hline $\mathrm{Hb}, \mathrm{g} / \mathrm{dL}$ & $13.7( \pm 1.5)$ & $14.1( \pm 1.3)$ & $13.6( \pm 1.6)$ & 0.2 \\
\hline Follow-up, months & $5.2( \pm 4.3)$ & $4.7( \pm 4.7)$ & $5.4( \pm 4.0)$ & 0.5 \\
\hline \multicolumn{5}{|l|}{ Comorbidities } \\
\hline Diabetes, $n(\%)$ & 5 (i.e., 7.0) & 1 (i.e., 4.3) & 4 (i.e., 8.3) & 0.5 \\
\hline $\mathrm{BMI}, \mathrm{kg} / \mathrm{m}^{2}$ & $26.7( \pm 6.6)$ & $25.7( \pm 4.0)$ & $27.1( \pm 7.8)$ & 0.3 \\
\hline Smokers, $n(\%)$ & 14 (i.e., 19.7) & 6 (i.e., 26.6) & 8 (i.e., 16.6) & 0.3 \\
\hline Steroid use, $n(\%)$ & 1 (i.e., 1.4) & 0 & 1 (i.e., 2.1) & 0.5 \\
\hline
\end{tabular}

Statistically significant values are in bold. Statistical significance was set at $p<0.05$. DBS, deep brain stimulation; OCD, obsessive compulsive disorder; IPG, implanted pulse generator; CRP, C-reactive protein.

\section{Results}

\section{Demographic Data}

We included a total of 71 patients in whom IPGs were removed as part of an exchange due to depletion of the battery between May 1,2019 and November 15, 2020. The mean patient age $( \pm S D)$ was $64.5( \pm 15.3$, range $24-88)$ years. Thirty-eight (i.e., 53.6\%) patients were male. Laboratory values at admission were CRP $7.2( \pm 12.9) \mathrm{mg} / \mathrm{L}$, and the white blood cell count $6.5( \pm 1.2) / \mathrm{nL}$. Indications for DBS were Parkinson's disease $(n=38)$, dystonia $(n=$ $22)$, essential tremor $(n=9)$, obsessive compulsive disor$\operatorname{der}(n=1)$, and depression $(n=1)$. Devices from 2 manufacturers were used. In detail, 59 patients had a Medtronic $^{\mathrm{TM}}$ device (56 Activa $^{\mathrm{TM}}$ PC, two Kinetra ${ }^{\mathrm{TM}}$, and one Soletra $\left.{ }^{\mathrm{TM}}\right)$, and 12 patients received a Boston Scientific ${ }^{\mathrm{TM}}$ device (eleven Vercise ${ }^{\mathrm{TM}} \mathrm{PC}$ and one Vercise Genus ${ }^{\mathrm{TM}}$ $\mathrm{P} 16)$. The demographic data regarding comorbidities (diabetes, BMI, smoking status, and steroid use) were similar between patients with positive and negative sonication results. The mean time between stereotactic implantation of DBS leads and exchange of the current IPG was 6.6 $( \pm 3.4)$ years (range 16 months -15.8 years). A mean of 1.1
( \pm 1.1 , range $0-5)$ former IPG exchanges was documented. Twenty-one patients had their 1st IPG exchange after initial implantation (Table 1). One of the initial implantations was performed in the same procedure as the lead implantation, while all the remaining implantations were performed in staged procedures with a duration of 54.3 $( \pm 16.7)$ minutes for the IPG implantation. There was no difference between patients with positive and negative sonication results $(48.3[ \pm 14.6]$ minutes vs. $57.2[ \pm 16.9]$ minutes; $p=0.3$ ). The mean duration of the former IPG exchanges of patients who had multiple former exchanges was $35.7( \pm 18.2)$ minutes, with no difference between patients with positive and negative sonication results (35.8 $[ \pm 18.2]$ minutes vs. $33.6[ \pm 17.4]$ minutes, $p=0.3)$.

\section{Microbiological Findings}

In 23 of 71 (i.e., 32.4\%) patients, a positive sonication culture was found. In 2 patients, 2 pathogens were detected simultaneously. Four low-virulent pathogens were found. The most common pathogens were Cutibacterium acnes (formerly known as Propionibacterium acnes) (17 pathogens, 68\%) and coagulase-negative Staphylococci (7 pathogens, $28 \%$ - 3 [i.e., 12\%] Staph. saccharolyticus,
10

Stereotact Funct Neurosurg 2022;100:8-13 DOI: $10.1159 / 000517472$
Spindler/Faust/Finger/Schneider/Bayerl/ Trampuz/Kühn/Vajkoczy/Prinz 


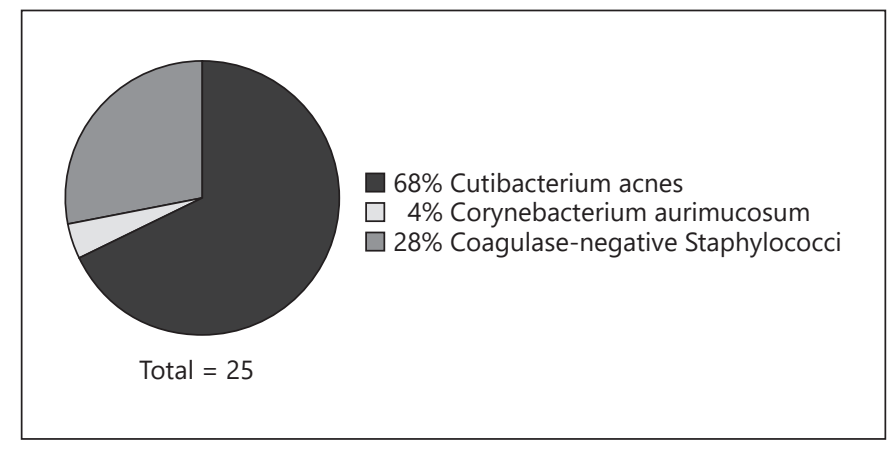

Fig. 1. Distribution of pathogens. Out of 25 low-virulent pathogens that were found in the sonication fluid, 17 (i.e., 68\%) were Cutibacterium acnes, 1 (i.e., 4\%) Corynebacterium aurimucosum, and 7 (i.e., 28\%) coagulase-negative Staphylococci.

3 [i.e., 12\%] Staph. hominis, and 1 [i.e., 4\%] Staph.haemolyticus) (see Fig. 1).

Men were more likely to have positive sonication results (17 [i.e., $73.9 \%$ ]). There was no difference between patients with positive $(n=23)$ and negative $(n=48)$ sonication results regarding age $(62.5 \pm 15.3$ vs. $65.5 \pm 15.2$ years, $p=0.4$ ), comorbidities, underlying indication for DBS, time between initial DBS surgery and explantation of the IPG ( $6.8 \pm 4.0$ vs. $6.5 \pm 2.9$ years, $p=0.8)$, number of former replacements of IPGs $(2.1 \pm 1.0$ vs. $2.1 \pm 1.1$, $p=0.9)$, and laboratory values at admission: CRP (1.8 \pm 0.8 vs. $10.3 \pm 15.3 \mathrm{mg} / \mathrm{L}, p=0.2)$ and the white blood cell count ( $6.2 \pm 0.9$ vs. $6.8 \pm 1.4 / \mathrm{nL}, p=0.5)$ (shown in Table 1).

\section{Clinical Follow-Up}

All patients were followed up postoperatively in the outpatient department of our institution. The mean follow-up was $5.2 \pm 4.3$ (range $0-16$ ) months. Thirty-one (i.e., 43.7\%) had a follow-up of $>6$ months. Within that period, no patient developed SSI or systemic infection, although 19 (i.e., 61.2\%) patients already had multiple IPG replacements in the past.

\section{Discussion}

This study has the following main findings: (1) colonization of the IPGs with low-virulent pathogens is common in patients without clinical signs of infection; (2) in our patient cohort, Cutibacterium acnes and coagulasenegative Staphylococci were the 2 most frequent pathogens; and (3) none of the patients with bacterial colonization developed a manifest infection.

Sonication of Implanted Pulse Generators
DBS has become a well-established treatment for a variety of conditions over the last decades $[1,2]$. Multiple surgeries are an essential part in the postoperative course of DBS patients if nonrechargeable IPGs are applied. In fact, infection is the most common complication following DBS device replacement. Interestingly, the risk of infection following IPG replacement is described to be 3 times higher than that after initial DBS surgery [13]. So far, the rate of subclinical infections is unknown, and sonication to detect implant-associated biofilms has not been applied in the field of DBS surgery. Sensitivity and specificity of sonication have been demonstrated as significantly higher than those of standard cultures and swabs with regard to detection of implantassociated infections [14-17,23], therefore we dispensed with collecting swabs for conventional microbiology. By analyzing the data of more than 70 patients, we clearly demonstrate that colonization of the IPG with low-virulent pathogens is common in patients without clinical signs of infection, as in about one-third of the patients a positive sonication culture was found. This rate is in line with previous findings reporting bacterial colonization of electrophysiological cardiac devices, breast implant, and spinal implants in clinically aseptic patients $[20,24$, 25].

The common method in case of implant-associated infections in DBS is device removal or a lead/electrodesparing procedure with partial explantation of the device. Before reimplantation, 2- to 3-month antimicrobial treatment until the infection is cured has been recommended [5, 18, 26]. Recently, Bjerknes et al. [11] suggested that complete explantation and antibiotic treatment until reimplantation should only be considered in cases with severe symptoms and high-virulent pathogens, while in other infections, an initial attempt with solely antibiotic treatment should be considered. Another more individual treatment is considered by Bernstein et al. [9] They suggest that the decision whether to remove hardware or a solely antibiotic treatment with hardware left in place has to consider the impact of adverse effects in case of hardware removal. The biofilm concept is one reason for those different strategies in salvage treatment for implant-associated infections. To the best of our knowledge, our study is the first study applying sonication in the field of IPG replacement surgery, clearly showing a high frequency of bacterial colonization with low-virulent pathogens in clinically aseptic patients. Within the follow-up period, bacterial colonization with low-virulent bacteria did not lead to manifest infections in our cohort.

Stereotact Funct Neurosurg 2022;100:8-13 DOI: $10.1159 / 000517472$ 
The intraoperative application of local vancomycin powder is another matter of debate within the field. While several authors recommend standard usage of intraoperative vancomycin to reduce the risk of SSI $[7,8]$, other studies did not report a decrease in the infection rate [5, 9]. Staphylococcus species were found to be the main causative pathogen of purulent infections [7]. In our cohort, we found Cutibacterium acnes to be the most common pathogen (68.0\% of positive sonication culture). Since Cutibacterium acnes is sensitive to vancomycin [27], a reduced rate of infections could be aimed in the aforementioned studies, even though Staphylococcus species have not been the causing pathogen. Although we refrain from usage of vancomycin and/or further antibiotic treatment of the patients with detection of low-virulent pathogens, none of our patients manifested infection during the follow-up period.

A limitation of our study is the relatively short followup period of $5.2 \pm 4.3$ months, as an infection, particularly due to organisms of low virulence, tends to manifest only over a longer follow-up period. Although a number of recent publications have reported a significant association of low-virulent pathogens in patients with no clinical signs of infection but implant failure with regard to spinal implants $[22,28]$, currently, evidence for the impact of low-virulent colonization in neurosurgical implants is missing. As the evidence for the relevance of subclinical infection with low-virulent pathogens is very limited, even a long-term antimicrobial treatment might not be justified, especially with respect to relevant side effects of long-term antibiotic treatment and drug interactions. Especially as in the case of DBS, implant removal is associated with significant morbidity and inconvenience for the patient as symptoms recur during the implant-free interval. Therefore, we do not recommend antibiotic eradication or removal of hardware in case of low-virulent pathogen detection in DBS. The long-term results of our study will clarify the role of low-virulent pathogen colonization in the development of delayed implant-associated infections.

\section{Statement of Ethics}

The study was conducted in accordance with the Declaration of Helsinki and approved by the Local Ethics Committee (No. EA2/231/20). Patient consent was not required for this prospective observational study as sonication was performed as part of the routine microbiological investigation.

\section{Conflict of Interest Statement}

All the authors have no conflicts of interest to declare. The authors have no personal, financial, or institutional interest in any of the drugs, materials, or devices described in this article.

\section{Funding Sources}

We acknowledge support from the German Research Foundation (DFG) and the Open Access Publication Fund of Charité Universitätsmedizin Berlin.

\section{Author Contributions}

Philipp Spindler, MD: concept and design, acquisition, analysis, and interpretation of data for the work; drafting the work; final approval of the version to be published; and agreement to be accountable for all aspects of the work in ensuring that questions related to the accuracy or integrity of any part of the work are appropriately investigated and resolved.

Katharina Faust, MD: concept and design; acquisition of data for the work; critical revision for important intellectual content of the work; final approval of the version to be published; and agreement to be accountable for all aspects of the work in ensuring that questions related to the accuracy or integrity of any part of the work are appropriately investigated and resolved.

Tobias Finger, MD: interpretation of data for the work; critical revision for important intellectual content of the work; final approval of the version to be published; and agreement to be accountable for all aspects of the work in ensuring that questions related to the accuracy or integrity of any part of the work are appropriately investigated and resolved.

Gerd-Helge Schneider, MD: acquisition of data for the work; critical revision for important intellectual content of the work; final approval of the version to be published; and agreement to be accountable for all aspects of the work in ensuring that questions related to the accuracy or integrity of any part of the work are appropriately investigated and resolved.

Simon Bayerl, MD: concept and design of the work; critical revision for important intellectual content of the work; final approval of the version to be published; and agreement to be accountable for all aspects of the work in ensuring that questions related to the accuracy or integrity of any part of the work are appropriately investigated and resolved.

Andrej Trampuz, MD: concept and design of the work; critical revision for important intellectual content of the work; final approval of the version to be published; and agreement to be accountable for all aspects of the work in ensuring that questions related to the accuracy or integrity of any part of the work are appropriately investigated and resolved.

Andrea A. Kühn, MD: interpretation of data for the work; critical revision for important intellectual content of the work; final approval of the version to be published; and agreement to be accountable for all aspects of the work in ensuring that questions related to the accuracy or integrity of any part of the work are appropriately investigated and resolved. 
Peter Vajkoczy, MD: interpretation of data for the work; critical revision for important intellectual content of the work; final approval of the version to be published; and agreement to be accountable for all aspects of the work in ensuring that questions related to the accuracy or integrity of any part of the work are appropriately investigated and resolved.
Vincent Prinz, MD: concept and design; interpretation of data for the work; drafting the work; final approval of the version to be published; and agreement to be accountable for all aspects of the work in ensuring that questions related to the accuracy or integrity of any part of the work are appropriately investigated and resolved.

\section{References}

1 Miocinovic S, Somayajula S, Chitnis S, Vitek JL. History, applications, and mechanisms of deep brain stimulation. JAMA Neurol. 2013; 70(2):163-71.

2 Lozano AM, Lipsman N, Bergman H, Brown P, Chabardes S, Chang JW, et al. Deep brain stimulation: current challenges and future directions. Nat Rev Neurol. 2019;15(3):148-60.

3 van Riesen C, Tsironis G, Gruber D, Klostermann F, Krause P, Schneider GH, et al. Disease-specific longevity of impulse generators in deep brain stimulation and review of the literature. J Neural Transm. 2016;123(6): 621-30.

4 Verberk JDM, Meijs AP, Vos MC, Schreurs LMA, Geerlings SE, De Greeff SC, et al. Contribution of prior, multiple-, and repetitive surgeries to the risk of surgical site infections in the Netherlands. Infect Control Hosp Epidemiol. 2017;38(11):1298-305.

5 Atchley TJ, Laskay NMB, Sherrod BA, Rahman AKMF, Walker HC, Guthrie BL. Reoperation for device infection and erosion following deep brain stimulation implantable pulse generator placement. J Neurosurg. 2020;133(2):403-10.

6 Bhatia R, Dalton A, Richards M, Hopkins C, Aziz T, Nandi D. The incidence of deep brain stimulator hardware infection: the effect of change in antibiotic prophylaxis regimen and review of the literature. Br J Neurosurg. 2011; 25(5):625-31.

7 Pepper J, Meliak L, Akram H, Hyam J, Milabo C, Candelario J, et al. Changing of the guard: reducing infection when replacing neural pacemakers. J Neurosurg. 2017;126(4):116572.

8 Miller JP, Acar F, Burchiel KJ. Significant reduction in stereotactic and functional neurosurgical hardware infection after local neomycin/polymyxin application: clinical article. J Neurosurg. 2009;110(2):247-50.

9 Bernstein JE, Kashyap S, Ray K, Ananda A. Infections in deep brain stimulator surgery. Cureus. 2019;11(8):e5440-8.
10 Sillay KA, Larson PS, Starr PA. Deep brain stimulator hardware-related infections: incidence and management in a large series. J Neurosurg. 2005;62(3):360-6.

11 Bjerknes S, Skogseid IM, Sæhle T, Dietrichs E, Toft M. Surgical site infections after deep brain stimulation surgery: frequency, characteristics and management in a 10-year period. PLoS One. 2014;9(8):e105288.

12 Van Epps JS, Younger JG. Implantable device-related infection. Shock. 2016;46(6): 597-608.

13 Pepper J, Zrinzo L, Mirza B, Foltynie T, Limousin P, Hariz M. The risk of hardware infection in deep brain stimulation surgery is greater at impulse generator replacement than at the primary procedure. Stereotact Funct Neurosurg. 2013;91(1):56-65.

14 Costerton JW, Stewart PS, Greenberg EP. Bacterial biofilms: a common cause of persistent infections. Science. 1999;284(5418): 1318-22.

15 Jost GF, Wasner M, Taub E, Walti L, Mariani L, Trampuz A. Sonication of catheter tips for improved detection of microorganisms on external ventricular drains and ventriculoperitoneal shunts. J Clin Neurosci. 2014; 21(4):578-82.

16 Prinz V, Bayerl S, Renz N, Trampuz A, Vajkoczy P, Finger T. Sonication improves pathogen detection in ventriculoperitoneal shunt-associated infections. Neurosurgery. 2019;85(4):516-23.

17 Sampedro MF, Huddleston PM, Piper KE, Karau MJ, Dekutoski MB, Yaszemski MJ, et al. A biofilm approach to detect bacteria on removed spinal implants. Spine. 2010;35(12): 1218-24.

18 Conen A, Fux CA, Vajkoczy P, Trampuz A. Management of infections associated with neurosurgical implanted devices. Expert Rev Anti Infect Ther. 2017;15(3):241-55.

19 Butenschoen VM, Seifert M, Meyer B, Krieg SM. Presence of Propionibacterium acnes in patients with aseptic bone graft resorption after cranioplasty: preliminary evidence for low-grade infection. J Neurosurg. 2019 Aug: 1-6. Online ahead of print.
20 Prinz V, Bayerl S, Renz N, Trampuz A, Czabanka M, Woitzik J, et al. High frequency of low-virulent microorganisms detected by sonication of pedicle screws: a potential cause for implant failure. J Neurosurg Spine. 2019; 31:424-9.

21 Bürger J, Akgün D, Strube P, Putzier M, Pumberger $\mathrm{M}$. Sonication of removed implants improves microbiological diagnosis of postoperative spinal infections. Eur Spine J. 2019; 28(4):768-74.

22 Pumberger M, Bürger J, Strube P, Akgün D, Putzier M. Unexpected positive cultures in presumed aseptic revision spine surgery using sonication. Bone Joint J. 2019;101-B(5):6214.

23 Trampuz A, Piper KE, Jacobson MJ, Hanssen AD, Unni KK, Osmon DR, et al. Sonication of removed hip and knee prostheses for diagnosis of infection. N Engl J Med. 2007;357(7): 654-63.

24 Rohacek M, Weisser M, Kobza R, Schoenenberger AW, Pfyffer GE, Frei R, et al. Bacterial colonization and infection of electrophysiological cardiac devices detected with sonication and swab culture. Circulation. 2010; 121(15):1691-7.

25 Rieger UM, Mesina J, Kalbermatten DF, Haug M, Frey HP, Pico R, et al. Bacterial biofilms and capsular contracture in patients with breast implants. Br J Surg. 2013;100(6):76874 .

26 Sillay KA, Larson PS, Starr PA. Deep brain stimulator hardware-related infections: incidence and management in a large series. Neurosurgery. 2008;62(2):360-7.

27 Gharamti AA, Kanafani ZA. Cutibacterium (formerly Propionibacterium) acnes infections associated with implantable devices. Expert Rev Anti Infect Ther. 2017;15(12):1-12.

28 Prinz V, Vajkoczy P. Surgical revision strategies for postoperative spinal implant infections (PSII). J Spine Surg. 2020;6(4):777-84. 